\title{
Comparison of itraconazole, voriconazole, and posaconazole as oral antifungal prophylaxis in pediatric patients following allogeneic hematopoietic stem cell transplantation
}

\author{
M. Döring • O. Blume • S. Haufe • U. Hartmann • \\ A. Kimmig • C.-P. Schwarze • P. Lang • \\ R. Handgretinger • I. Müller
}

Received: 21 August 2013 / Accepted: 9 October 2013/Published online: 31 October 2013

(C) The Author(s) 2013. This article is published with open access at Springerlink.com

\begin{abstract}
Oral antifungal prophylaxis with extended-spectra azoles is widely used in pediatric patients after allogeneic hematopoietic stem cell transplantation (HSCT), while controlled studies for oral antifungal prophylaxis after bone marrow transplantation in children are not available. This survey analyzed patients who had received either itraconazole, voriconazole, or posaconazole. We focused on the safety, feasibility, and initial data of efficacy in a cohort of pediatric patients and adolescents after high-dose chemotherapy and HSCT. Fifty consecutive pediatric patients received itraconazole, 50 received voriconazole, and 50 pediatric patients received posaconazole after HSCT as oral antifungal prophylaxis. The observation period lasted from the start of oral prophylactic treatment with itraconazole, voriconazole, or posaconazole until two weeks after terminating the oral antifungal prophylaxis. No incidences of proven or probable invasive mycosis were observed during itraconazole, voriconazole, or posaconazole treatment. A total of five possible invasive fungal infections occurred, two in the itraconazole group ( $4 \%$ ) and three in the voriconazole group $(6 \%)$. The percentage of patients with adverse events potentially related to clinical drugs were $14 \%$ in the
\end{abstract}

\footnotetext{
M. Döring $(\bowtie) \cdot$ O. Blume $\cdot$ S. Haufe $\cdot$ A. Kimmig $\cdot$

C.-P. Schwarze $\cdot$ P. Lang $\cdot$ R. Handgretinger

Department of Pediatric Hematology and Oncology, University

Children's Hospital Tübingen, Hoppe-Seyler-St. 1, 72076 Tübingen,

Germany

e-mail: Michaela.Doering@med.uni-tuebingen.de

\section{U. Hartmann}

University Pharmacy, University Children's Hospital Tübingen,

Tübingen, Germany

I. Müller

Clinic of Pediatric Hematology and Oncology, University Medical

Center Hamburg-Eppendorf, Hamburg, Germany
}

voriconazole group, $12 \%$ in the itraconazole group, and $8 \%$ in the posaconazole group. Itraconazole, voriconazole, and posaconazole showed comparable efficacy as antifungal prophylaxis in pediatric patients after allogeneic HSCT.

\section{Introduction}

Invasive fungal infection is one of the most feared complications in immunocompromised pediatric patients after high-dose chemotherapy and allogeneic hematopoietic stem cell transplantation (HSCT). Post-transplantation immune deficiency, immune suppression, high-dose steroids, neutropenia, viral infections, and acute graft-versus-host disease (GvHD) are known risk factors for fungal infections, especially with Aspergillus spp. and Candida spp. [1, 2]. Antifungal prophylaxis early after transplantation is therefore indicated. The azole derivatives itraconazole and voriconazole provide initial coverage against Candida, Aspergillus, and other rare mold infections [3-5]. These antimycotics belong to the group of agents routinely used for the effective prevention and treatment of systemic fungal infections in patients with hemato-oncological malignancies and neutropenia [6-14]. An antifungal broad-spectrum azole rarely used in pediatric patients up to now, posaconazole, has been shown to be effective against Candida spp., Aspergillus spp., Cryptococcus spp., Zygomycetes spp., and Fusarium spp. in adults [15-18]. In contrast to other azoles, itraconazole and voriconazole, it provides only minimal inhibition of cytochrome C-dependent enzymes [19-21]. In adults with myelodysplastic syndrome or acute myeloid leukemia, posaconazole proved to be more effective than itraconazole and fluconazole for the prophylaxis of invasive fungal infections [22]. In adults with GvHD, posaconazole has emerged as the first choice for the prophylaxis of invasive 
aspergillosis [23]. In our clinic, we switched the antifungal prophylaxis to posaconazole in 2007 due to the low incidence of adverse events in adults and the observed breakthrough infections with the application of azoles other than posaconazole in the past $[22,23]$. We analyzed the first 60 pediatric patients under 12 years of age with hematooncological malignancies and non-malignancies who received posaconazole as antifungal prophylaxis after allogeneic HSCT [24]. Posaconazole at a dosage of $12 \mathrm{mg} / \mathrm{kg}$ body weight divided into three doses was a well-tolerated, safe, and effective oral antifungal prophylaxis in pediatric patients who underwent high-dose chemotherapy and HSCT. To compare the effectiveness of various azoles in pediatric patients, we chose a group of 50 pediatric patients that received posaconazole as antifungal prophylaxis after allogeneic HSCT. This group was compared to groups of pediatric patients of the same group size that received itraconazole or voriconazole as oral antifungal monoprophylaxis after allogeneic HSCT. We analyzed 50 consecutive patients in each group with the primary objective of obtaining initial data on efficacy, and secondary objectives of investigating safety and feasibility.

\section{Methods}

This analysis was conducted in accordance with the Declaration of Helsinki and performed with approval by the University Children's Hospital Tübingen's Institutional Review Board.

Patients, study design, and setting

This single-center survey at the University Children's Hospital Tübingen analyzed the data of 150 pediatric patients under 18 years of age who received antifungal monoprophylaxis with either itraconazole, voriconazole, or posaconazole after allogeneic HSCT. Each of the three azole groups included data from 50 consecutive pediatric patients. None of the children included in this analysis had an invasive fungal infection prior to the planned allogeneic HSCT. Baseline demographics, clinical factors, treatment-related adverse events, and survival were abstracted from clinical and research records on all patients and maintained on a prospective basis. The primary objective of this study was to investigate breakthrough infections. The secondary objectives were to analyze the safety and feasibility of the three regimens. The observation period was defined as the period from the day before the start of antifungal monoprophylaxis with itraconazole, voriconazole, or posaconazole through the date two weeks after the completion of oral antimycotic prophylaxis, up to a maximum of 220 days after HSCT.
Administration of three azoles and co-medication

Each of the 50 pediatric patients and adolescents received itraconazole at a dosage of $2 \times 5 \mathrm{mg}$ per $\mathrm{kg}$ of body weight daily and voriconazole $2 \times 100 \mathrm{mg}$ daily (body weight $<40 \mathrm{~kg}$ ) or $2 \times 200 \mathrm{mg}$ (body weight $>40 \mathrm{~kg}$ ). According to the posaconazole level analysis of the previous survey of 60 pediatric patients under 12 years of age in our clinic, the dosage of posaconazole was $3 \times 4 \mathrm{mg}$ per $\mathrm{kg}$ of body weight daily (maximum $3 \times 200 \mathrm{mg}$ /day) in this analysis [24]. Pediatric patients received aciclovir, cotrimoxazole, and penicillin $\mathrm{V}$ simultaneously with the oral azoles in each group.

\section{Assessment of efficacy}

Proven, probable, and possible invasive fungal infections were classified according to the National Institute of Allergy and Infectious Diseases Mycoses Study Group (EORTC) criteria $[25,26]$. The analysis of galactomannan antigen was measured until a minimum of day 100 after HSCT at least once a week by the PlateliaTM Aspergillus enzyme-linked immunosorbent assay (ELISA) (Bio-Rad Laboratories, Munich, Germany).

\section{Assessment of safety and tolerance}

Treatment-related side effects during the observation period were analyzed and graded according to current US National Cancer Institute's Common Terminology Criteria for Adverse Events [27]. Blood tests of electrolytes, hepatic, and kidney parameters were statistically analyzed at the baseline time, defined as the day before the start of oral antifungal monoprophylaxis, along with the maximum and minimum values during the therapy, as well as the value at the end of antifungal prophylaxis, defined as the last day of treatment.

Measurement of cyclosporin A (CsA) levels in the blood was regularly performed in pediatric patients that received GvHD prophylaxis with CsA during the conditioning regimen and after HSCT. This occurred at least twice per week. Trough levels of CsA for pediatric patients who had received an allogeneic HSCT from a matched donor were between 150 $180 \mu \mathrm{g} / \mathrm{L}$. Recipients of a haploidentical graft from their parents received mycophenolate mofetil instead.

Statistical analysis

The statistical comparison of the differences between the results and the normal range values was performed by a onesample $t$-test, taking into account the $95 \%$ confidence intervals. The inferential statistical analysis between the baseline values as well as the maximum and minimum parameters and the parameters at the cessation of antifungal monoprophylaxis was done by the Wilcoxon matched-pairs 
signed-ranks test. CsA levels during antifungal prophylaxis were analyzed by the Friedman two-way analysis of variance by ranks, due to non-normally distributed values in at least one group or day, making a parametric analysis of variance (ANOVA) for repeated measures not appropriate. The analysis of the hepatic and kidney parameters are presented as mean values \pm standard deviation. $p$-values of $\leq 0.05(*), p \leq$ $0.01(* *)$, and $p \leq 0.001(* * *)$ were defined as significant. Values were only considered significant above the ageadjusted reference. XLStat2010 (AddinSoft, Paris, France) was used for the statistical analysis. Graphs were created with GraphPad Prism 4 for Windows, version 4.03.

\section{Results}

Patients' characteristics according to azole antifungal prophylaxis

The comparative analysis of the efficacy, safety, and feasibility of itraconazole, voriconazole, and posaconazole was performed in a total of 150 pediatric patients (69 female, 81 males) between $0.6-17.7$ years of age with hematooncological malignancies, non-malignant diseases, and inborn errors of metabolism. For the most part, the three patient groups were similar. Significant differences in clinical characteristics were noted regarding the myeloablative conditioning regimen $(p=0.013)$ and the donor, especially the mismatched unrelated donor $(p=0.005)$. The differences were mostly found in the itraconazole group in relation to the voriconazole and posaconazole groups. Patient and clinical characteristics for each of the groups are summarized in Tables 1 and 2. All patients were given one of the azoles as primary oral antifungal monoprophylaxis after change from intravenous antifungal prophylaxis following allogeneic HSCT, i.e., 2 to 3 days before clinical discharge. The analysis was carried out on 50 consecutive pediatric patients in our clinic, who received itraconazole from 2006 to 2007 before change of the antifungal monoprophylaxis to posaconazole in 2007. Fifty consecutive pediatric patients received voriconazole as oral antifungal monoprophylaxis after allogeneic HSCT between 2006 and 2010. There were two reasons for using monoprophylaxis with voriconazole. In general, the pediatric patients were children that had been treated for hematological disease before transplantation at other clinics and had already received prophylaxis with voriconazole. The others were children who preferred tablets than an oral suspension. This is also the reason why the survey period for children in the voriconazole group was 4 years (2006-2010). Fifty pediatric patients received posaconazole from August 2010 to December 2011, directly after our first publicized analysis of 60 pediatric patients under 12 years of age receiving posaconazole as antifungal prophylaxis [24].
Mortality

A total of 9 of $150(6 \%)$ pediatric patients, five of them in the itraconazole group, two in the voriconazole group, and two in the posaconazole group, died of causes other than invasive fungal infection during the observation period. The causes of death were bacterial sepsis in one case, kidney failure in one case, and in seven cases, a relapse of the underlying disease. These patients were included in the analysis until antifungal prophylaxis with oral antifungal azole was discontinued.

Intravenously pre-azole prophylaxis and discontinuation during oral azole prophylaxis

The intravenous antifungal prophylaxis before the switch to an oral antifungal monoprophylaxis consisted of liposomal amphotericin B from day +1 after HSCT for all 50 pediatric patients within the itraconazole group; in the voriconazole group, 33 pediatric patients received liposomal amphotericin $\mathrm{B}$ and 17 patients caspofungin prior to oral prophylaxis, and in the posaconazole group, four patients received liposomal amphotericin B and 46 patients caspofungin. Due to posttransplant complications, a total of ten patients were changed back to an intravenous antifungal prophylaxis during oral antifungal prophylaxis during the treatment period with oral antifungal prophylaxis: four cases in the itraconazole group, three cases in the voriconazole group, and three cases in the posaconazole group. The reasons were bacterial sepsis in three cases, severe bacterial infection in one patient, viremia in three cases, and acute intestinal GvHD grades II or III in three cases at discharge.

\section{Efficacy analysis}

All 150 pediatric patients analyzed in this study were included in the efficacy analysis. In all three groups, no case of proven or probable invasive fungal infection according to the EORTC guidelines occurred during the observation period $[25,26]$. Possible invasive fungal infections were observed in $2(4 \%)$ out of 50 pediatric patients in the itraconazole group, as well as in $3(6 \%)$ out of 50 cases in the voriconazole group. There were no possible invasive fungal infections observed in the posaconazole group.

We found no significant differences comparing all three drugs $(n=2 / 3 / 0)$ by tests for differences in proportions $(k$ sample test: $p=0.235 ; \mathrm{df}=2$; Chi-square $=2.896$; Monte Carlo simulation test: $p=0.174 ; \mathrm{df}=2$; Chi-square $=2.896$ ), and no statistically significant pairwise differences of posaconazole to the other drugs ( $n=0 / 2$, Fisher's exact test, $p=0.495 ; n=0 / 3$, Fisher's exact test, $p=0.242$ ). In the itraconazole and voriconazole groups, all five possible invasive infections were with Aspergillus spp., with an increased galactomannan 
Table 1 Patient characteristics

ALL: acute lymphoblastic

leukemia; AML: acute

myelogenous leukemia; CML:

chronic myeloid leukemia; CsA:

cyclosporin A, JMML: juvenile

myelomonocytic leukemia;

MAC: myeloablative

conditioning; MDS:

myelodysplastic syndromes;

MFD: matched family donor;

MMFD: mismatched family

donor; MMUD: mismatched

unrelated donor; MTX:

methotrexate; MUD: matched

unrelated donor; NHL: non-

Hodgkin lymphoma; RIC:

reduced intensity conditioning;

TBI: total body irradiation; TLI:

total lymphoid irradiation

$p$-value: according to the comparison of $k$ proportions (Chi-square test)

\begin{tabular}{|c|c|c|c|c|}
\hline Characteristic & $\begin{array}{l}\text { Itraconazole } \\
(n=50)\end{array}$ & $\begin{array}{l}\text { Voriconazole } \\
(n=50)\end{array}$ & $\begin{array}{l}\text { Posaconazole } \\
(n=50)\end{array}$ & $p$-Value \\
\hline \multicolumn{5}{|l|}{ No. of patients $(\%)$} \\
\hline \multicolumn{5}{|l|}{ Gender } \\
\hline Male & $31(62)$ & $23(46)$ & $27(54)$ & 0.276 \\
\hline Female & $19(38)$ & $27(54)$ & $23(46)$ & 0.276 \\
\hline \multicolumn{5}{|l|}{ Age group } \\
\hline$<6$ years & $21(42)$ & $25(50)$ & $20(40)$ & 0.567 \\
\hline $6-11$ years & $12(24)$ & $14(28)$ & $13(26)$ & 0.901 \\
\hline 12 to $<18$ years & $17(34)$ & $11(22)$ & $17(34)$ & 0.319 \\
\hline \multicolumn{5}{|l|}{ Primary diagnosis } \\
\hline ALL & $17(34)$ & $16(32)$ & $9(18)$ & 0.152 \\
\hline AML & $11(22)$ & $8(16)$ & $4(8)$ & 0.150 \\
\hline JMML & - & $3(6)$ & - & 0.047 \\
\hline CML & $1(2)$ & $1(2)$ & - & 0.602 \\
\hline MDS & $6(12)$ & $1(2)$ & $5(10)$ & 0.149 \\
\hline NHL & - & $2(4)$ & $1(2)$ & 0.360 \\
\hline Solid tumors & $6(12)$ & $5(10)$ & $8(16)$ & 0.656 \\
\hline Aplastic anemia & $2(4)$ & $9(18)$ & $14(28)$ & 0.005 \\
\hline Neurometabolic disease & $4(8)$ & $2(4)$ & $2(4)$ & 0.590 \\
\hline Immunodeficiency & $2(4)$ & $4(8)$ & $6(12)$ & 0.337 \\
\hline Chédiak-Higashi syndrome & $1(2)$ & - & $1(2)$ & 0.602 \\
\hline \multicolumn{5}{|l|}{ Donor } \\
\hline MUD & $13(26)$ & $13(26)$ & $14(28)$ & 0.966 \\
\hline MMUD & $8(16)$ & $1(2)$ & $1(2)$ & 0.005 \\
\hline MMFD & $18(36)$ & $31(62)$ & $23(46)$ & 0.032 \\
\hline MFD & $11(22)$ & $5(10)$ & $12(24)$ & 0.151 \\
\hline \multicolumn{5}{|l|}{ Radiation } \\
\hline TBI & $13(26)$ & $6(12)$ & $6(12)$ & 0.095 \\
\hline TLI & $2(4)$ & $4(8)$ & $3(6)$ & 0.701 \\
\hline \multicolumn{5}{|l|}{ Conditioning regimen } \\
\hline MAC & $33(66)$ & $22(44)$ & $19(38)$ & 0.013 \\
\hline RIC & $17(34)$ & $28(56)$ & $30(60)$ & 0.020 \\
\hline No conditioning & - & - & $1(2)$ & 0.365 \\
\hline \multicolumn{5}{|l|}{ GvHD prophylaxis } \\
\hline Thymoglobulin & $26(52)$ & $18(36)$ & $31(62)$ & 0.032 \\
\hline Muromonab & $13(26)$ & $26(52)$ & $14(28)$ & 0.010 \\
\hline Mycophenolate mofetil & $15(30)$ & $17(34)$ & $22(44)$ & 0.324 \\
\hline CsA & $7(14)$ & $17(34)$ & $9(18)$ & 0.038 \\
\hline $\mathrm{CsA}+\mathrm{MTX}$ & $26(52)$ & $14(28)$ & $17(34)$ & 0.036 \\
\hline MTX & $1(2)$ & - & - & 0.365 \\
\hline \multicolumn{5}{|l|}{ Systemic corticosteroids } \\
\hline During transplant period & $28(56)$ & $24(48)$ & $19(38)$ & 0.196 \\
\hline At time of discharge & $8(16)$ & $12(24)$ & $7(14)$ & 0.387 \\
\hline \multicolumn{5}{|l|}{ GvHD } \\
\hline Grade I & $12(24)$ & $11(22)$ & $14(28)$ & 0.778 \\
\hline Grade II & $10(20)$ & $7(14)$ & $7(14)$ & 0.640 \\
\hline Grade III & - & $1(2)$ & $1(2)$ & 0.602 \\
\hline Grade IV & - & - & - & - \\
\hline Chronic limited & $1(2)$ & $1(2)$ & - & 0.602 \\
\hline Chronic extensive & - & $1(2)$ & $1(2)$ & 0.602 \\
\hline
\end{tabular}


Table 2 Clinical characteristics

\begin{tabular}{llll}
\hline Characteristic & $\begin{array}{l}\text { Itraconazole } \\
(n=50)\end{array}$ & $\begin{array}{l}\text { Voriconazole } \\
(n=50)\end{array}$ & $\begin{array}{l}\text { Posaconazole } \\
(n=50)\end{array}$ \\
\hline $\begin{array}{l}\text { Median (range) } \\
\text { Age in years }\end{array}$ & $8.5(0.5-17.3)$ & $7.0(0.75-17.8)$ & $8.0(1.6-17.7)$ \\
$\begin{array}{l}\text { Observation period } \\
\quad \text { until day after }\end{array}$ & $168(17-220)$ & $171(18-216)$ & $153(15-218)$ \\
$\quad$ HSCT $)$ & & & \\
$\begin{array}{l}\text { Treatment period, days } \\
\text { Duration of neutropenia } \\
\quad(\leq 500 \text { cells } / \mu \mathrm{L}),\end{array}$ & $16(9-46)$ & $11(9-27)$ & $14(9-31)$ \\
$\quad$ days & & & \\
\hline
\end{tabular}

antigen that was detected in more than two consecutive blood samples.

Safety and feasibility analysis

Adverse events potentially related to itraconazole treatment were observed in six patients $(12.0 \%)$, in seven $(14.0 \%)$ related to voriconazole, and in four $(8.0 \%)$ pediatric patients related to posaconazole treatment (Table 3). These adverse events were of severity grades I or II [27]. No significant difference was found between the three antimycotics concerning the percentage of potentially drug-related adverse events by the $k$-sample tests for differences in proportions ( $p=$ $0.6285 ; \mathrm{df}=2$; Chi-square $=0.9288$ ). Oral antifungal prophylaxis was stopped in three of the six cases treated with itraconazole, in four of the seven receiving voriconazole, and in three of the four receiving posaconazole. The change of oral antifungal prophylaxis was from itraconazole to voriconazole, from voriconazole to posaconazole, and from posaconazole to voriconazole. These patients were included in the analysis up to the last day of their treatment with the initial azole. Reconstitution of hematopoiesis including leukocytes, neutrophils, lymphocyte subpopulations, and platelets proceeded in a timely fashion. Statistical analysis of the transaminases showed a significant increase beyond the upper normal limit of alanine aminotransferase (ALT, normal value $\leq 39 \mathrm{U} / \mathrm{L}$ ) and aspartate aminotransferase (AST, normal value $\leq 39 \mathrm{U} / \mathrm{L}$ ) (as shown by the one-sample $t$-test), and a significant difference between the baseline and maximum levels of ALT and AST (as shown by the Wilcoxon matched-pairs signed-ranks test) in all three groups without clinical symptoms (Fig. 1). Total bilirubin (normal value $\leq 1.1 \mathrm{mg} / \mathrm{dl}$ ) also increased during itraconazole, voriconazole, and posaconazole treatments, but remained within the age-adjusted normal range. The kidney parameters creatinine (normal value $\leq 0.7 \mathrm{mg} / \mathrm{dl}$ ) and urea (normal value $\leq 46 \mathrm{mg} / \mathrm{dl}$ ) showed an increase within all three groups during the antifungal monoprophylaxis, which were not significantly above age-adjusted reference values. Low potassium levels $<3.4 \mathrm{mmol} / \mathrm{L}$ were observed in $23(46 \%)$ of the patients in the itraconazole group, in 19 (38\%) of the voriconazole group, and in $3(6 \%)$ cases in the posaconazole group (Table 3 ). The serum electrolytes calcium (normal value $\geq 2.0 \mathrm{mmol} / \mathrm{L}$ ), phosphate (normal value $\geq 1.1 \mathrm{mmol} / \mathrm{L}$ ), and bicarbonate in the blood gas analyses (normal value $\geq 21 \mathrm{mmol} / \mathrm{L}$ ) remained in the normal range during antifungal monoprophylaxis with itraconazole, voriconazole, or posaconazole (Fig. 2).

\section{Cyclosporin A levels}

CsA levels during oral antifungal monoprophylaxis were evaluable in 18 patients in the itraconazole group, in 16 patients in the voriconazole group, and in 20 patients in the posaconazole group (Table 3). In all three groups, an increase but no significant differences of CsA levels were observed between days 2-3, 4-6, and 8-12 after the start of oral antifungal prophylaxis with itraconazole $(p=0.51)$, voriconazole $(p=0.73)$, and posaconazole $(p=0.28)$ using the Friedman test. CsA dosage was reduced in four $(22.2 \%)$ cases within the itraconazole group, in six cases $(37.5 \%)$ within the voriconazole group, and in seven (35\%) cases within the posaconazole group during the first 12 days of antifungal monoprophylaxis. The dose of CsA was reduced by up to $12 \%$ in the itraconazole group and in the voriconazole group, and up to $25 \%$ in the posaconazole group.

\section{Discussion}

Clinical guidelines provide recommendations for oral antifungal prophylaxis in adult patients. However, comparable guidelines for pediatric patients after allogeneic HSCT are based on insufficient data [28-30]. The very good results regarding the efficacy and low incidence of side effects of posaconazole in adults and breakthrough infections in immunocompromised pediatric patients with other azoles in our clinic was the rationale for changing to posaconazole for oral prophylaxis in pediatric patients [22, 23]. After the favorable results of our first analysis of posaconazole in 60 pediatric patients, the intention of this analysis was to assess another group of pediatric patients in regards to posaconazole prophylaxis [24]. We compared posaconazole with itraconazole and voriconazole during the initial and posttransplant period up to a maximum of 220 days after allogeneic HSCT in 150 pediatric patients. The efficacy of each drug was very good, as no proven or probable fungal invasive infection occurred in any of the three treatment groups during the observation period. In view of possible invasive fungal infections in the present analysis, posaconazole as antifungal prophylaxis after allogeneic 
Table 3 Clinical and laboratory adverse events during antifungal prophylaxis

\begin{tabular}{|c|c|c|c|c|}
\hline Characteristic & Itraconazole $(n=50)$ & Voriconazole $(n=50)$ & Posaconazole $(n=50)$ & $p$-Value \\
\hline \multicolumn{5}{|l|}{ No. of patients (\%) } \\
\hline \multicolumn{5}{|l|}{ Drug-related adverse events } \\
\hline Clinical (total) & $6(12)$ & $7(14)$ & $4(8)$ & 0.629 \\
\hline Fever & $1(2)$ & - & - & 0.365 \\
\hline Nausea & $2(4)$ & $2(4)$ & $3(6)$ & 0.861 \\
\hline Vomiting & $1(2)$ & - & $1(2)$ & 0.602 \\
\hline Diarrhea & - & $1(2)$ & - & 0.365 \\
\hline Exanthema & $2(4)$ & - & - & 0.132 \\
\hline Skin photosensitization & - & $2(4)$ & - & 0.132 \\
\hline Perspiration & - & $2(4)$ & - & 0.132 \\
\hline \multicolumn{5}{|c|}{ Increase in alanine aminotransferase } \\
\hline$>1.5 \times$ normal value $39 \mathrm{U} / \mathrm{L}$ & $17(34)$ & $7(14)$ & $8(16)$ & 0.027 \\
\hline$>2.5 \times$ normal value $39 \mathrm{U} / \mathrm{L}$ & $4(8)$ & $3(6)$ & $9(18)$ & 0.114 \\
\hline \multicolumn{5}{|c|}{ Increase in aspartate aminotransferase } \\
\hline$>1.5 \times$ normal value $39 \mathrm{U} / \mathrm{L}$ & $13(26)$ & $10(20)$ & $8(16)$ & 0.462 \\
\hline$>2.5 \times$ normal value $39 \mathrm{U} / \mathrm{L}$ & $2(4)$ & $2(4)$ & $5(10)$ & 0.345 \\
\hline \multicolumn{5}{|l|}{ Decrease in potassium } \\
\hline$<3.4 \mathrm{mmol} / \mathrm{L}$ & $22(44)$ & $18(36)$ & $3(6)$ & $<0.0001$ \\
\hline$<2.4 \mathrm{mmol} / \mathrm{L}$ & $1(2)$ & $1(2)$ & - & 0.602 \\
\hline \multicolumn{5}{|l|}{ Decrease in calcium } \\
\hline$<2.0 \mathrm{mmol} / \mathrm{L}$ & $6(12)$ & $11(22)$ & $2(4)$ & 0.025 \\
\hline$<1.8 \mathrm{mmol} / \mathrm{L}$ & $2(4)$ & $3(6)$ & - & 0.235 \\
\hline \multicolumn{5}{|l|}{ Decrease in phosphate } \\
\hline$<1.1 \mathrm{mmol} / \mathrm{L}$ & $11(22)$ & $11(22)$ & $10(20)$ & 0.961 \\
\hline$<0.8 \mathrm{mmol} / \mathrm{L}$ & $3(6)$ & $10(20)$ & $1(2)$ & 0.005 \\
\hline \multicolumn{5}{|l|}{ Decrease in bicarbonate } \\
\hline$<21 \mathrm{mmol} / \mathrm{L}$ & $11(22)$ & $17(34)$ & $10(20)$ & 0.220 \\
\hline$<18 \mathrm{mmol} / \mathrm{L}$ & $1(2)$ & - & - & 0.365 \\
\hline \multicolumn{5}{|l|}{ CsA level } \\
\hline$\geq 1.5 \times$ baseline days $2-3$ & $3(6)$ & $1(2)$ & $3(6)$ & 0.549 \\
\hline$\geq 2.0 \times$ baseline days $2-3$ & - & $2(4)$ & $1(2)$ & 0.360 \\
\hline$\geq 1.5 \times$ baseline days $4-6$ & - & $3(6)$ & $4(8)$ & 0.397 \\
\hline$\geq 2.0 \times$ baseline days $4-6$ & - & $3(6)$ & $3(6)$ & 0.876 \\
\hline$\geq 1.5 \times$ baseline days $8-12$ & - & $3(6)$ & - & 0.235 \\
\hline$\geq 2.0 \times$ baseline days $8-12$ & - & $2(4)$ & $1(2)$ & 0.773 \\
\hline
\end{tabular}

$p$-value: according to the comparison of $k$ proportions (Chi-square test)

HSCT seems to be more effective than antifungal prophylaxis with itraconazole or voriconazole after allogeneic HSCT.

However, due to the patient characteristic of the itraconazole and voriconazole groups, the risk profile for the occurrence of invasive fungal infections was slightly higher than for the posaconazole group, since there were fewer patients in this group, i.e., $n=19$ (38\%), who were receiving a myeloablative conditioning regimen. The itraconazole and voriconazole groups had $n=33(66 \%)$ and $n=22(44 \%)$ patients, respectively. In addition to our first 60 pediatric patients who received oral antifungal prophylaxis with posaconazole after allogeneic HSCT, the efficacy of posaconazole as antifungal therapy has also been reported in small groups of pediatric patients $[24,31,32]$. In a multicenter retrospective survey of 15 pediatric patients with invasive fungal infections, posaconazole has been shown to be an effective antifungal salvage therapy for proven and probable fungal infections [31]. In another retrospective survey, 12 of 15 pediatric patients had an invasive fungal infection with lung involvement [32]. In this survey, posaconazole given as rescue therapy improved significantly clinical-radiological signs in 9 of these 12 patients. 
Fig. 1 Hepatotoxicity. Values of liver enzymes and cholestasis parameters are shown on the day before the start of oral antifungal prophylaxis (baseline), maximum values during (maximum) and end of itraconazole (white columns), voriconazole (gray columns), and posaconazole (dark gray columns) treatment (end). a Mean and standard deviation (SD) of serum alanine aminotransferase (ALT) (normal value $\leq 39 \mathrm{U} / \mathrm{L}$ ). b Serum aspartate aminotransferase (AST) (normal value $\leq 39 \mathrm{U} / \mathrm{L}$ ). c Total bilirubin (normal value $\leq 1.1 \mathrm{mg} / \mathrm{dl}$ ). d Direct bilirubin (normal value $\leq 0.3 \mathrm{mg} / \mathrm{dl}$ ). e Serum alkaline phosphatase (AP) (normal value $\leq 320 \mathrm{U} / \mathrm{L}$ ). The horizontal line indicates the normal value. Statistical analysis of ALT and AST by the onesample $t$-test showed a significant increase beyond the upper normal limit. A significant increase (by the Wilcoxon matched-pairs signed-ranks tests) of ALT between baseline and maximum in all three groups, itraconazole $(p=0.0007)$, voriconazole $(p=0.0151)$, posaconazole $(p=0.00066)$, and a significant increase of AST during itraconazole $(p=0.0013)$, voriconazole $(p=0.0032)$, and posaconazole $(p=0.0024)$ treatment was detected. Total bilirubin, direct bilirubin, and alkaline phosphatase during itraconazole, voriconazole, and posaconazole treatment remained within the age-corrected normal range. None of these changes was clinically relevant
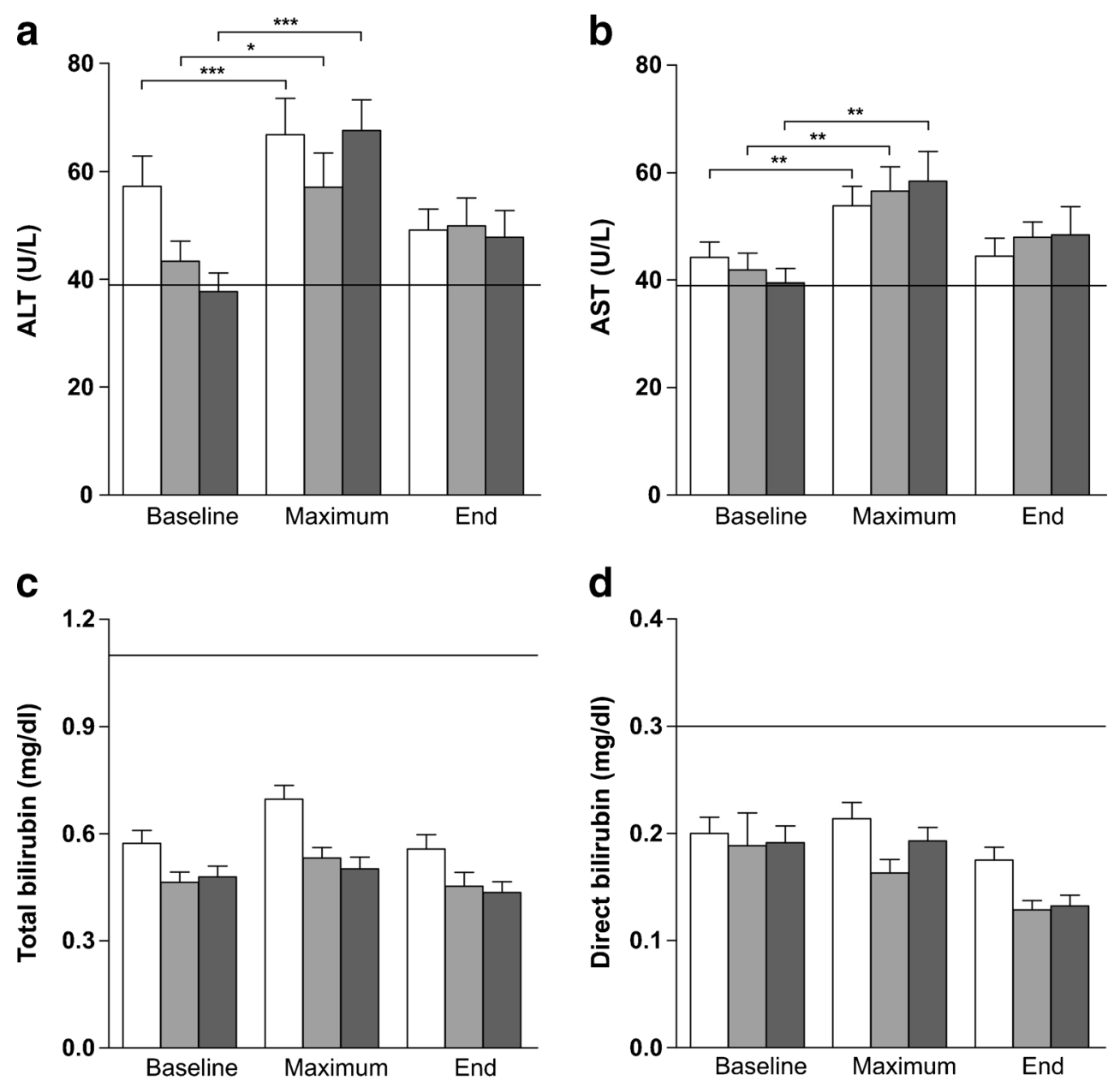

In view of the clinically relevant side effects, our analysis showed that there were fewer occurrences in the posaconazole $(8 \%)$ group than in the itraconazole $(12 \%)$ and voriconazole (14\%) groups. Power was low (16.2\%, post-hoc power analysis) to detect a difference between voriconazole and posaconazole treatment percentages of potentially drugrelated adverse events, and even lower for the other comparisons (between itraconazole and posaconazole, and itraconazole and voriconazole). Therefore, the fact that no significant difference was found must be cautiously interpreted [33]. The spectrum of clinically relevant side effects within the posaconazole group was limited to gastrointestinal complaints such as nausea and vomiting. Similar side effects were observed in $9(8.5 \%)$ of the 106 adults in another study, who were given antifungal prophylaxis with posaconazole after HSCT [34]. Itraconazole 
Fig. 2 Electrolytes. Mean and standard deviation (SD) of electrolytes in peripheral blood. a Potassium (normal value $>3.4 \mathrm{mmol} / \mathrm{L})$. b Calcium (normal value $>2.1 \mathrm{mmol} / \mathrm{L}$ ).

c Phosphate (normal

value $>0.8 \mathrm{mmol} / \mathrm{L}$. d

Bicarbonate (normal value $>21 \mathrm{mmol} / \mathrm{L}$ ) on the day before the start of oral antifungal prophylaxis (baseline), minimum values during (minimum) and end of itraconazole (white columns), voriconazole (gray columns), and posaconazole (dark gray columns) treatment (end). The horizontal line indicates the normal value. Statistical analysis by the one-sample $t$-test showed no significant decrease below the lower limit of the normal range during antifungal monoprophylaxis a

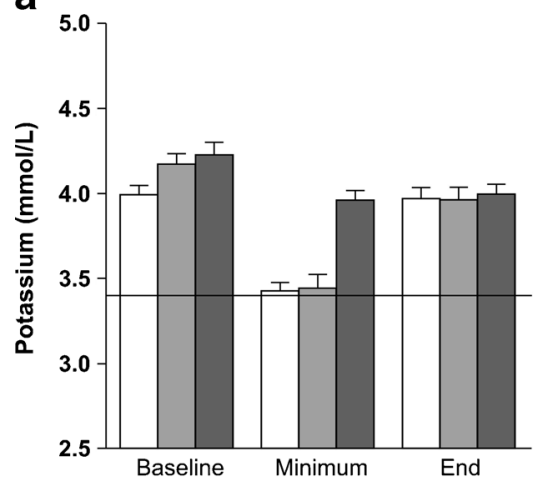

C

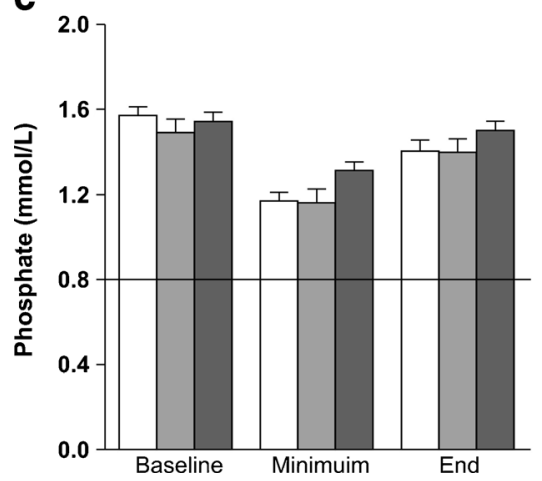

b

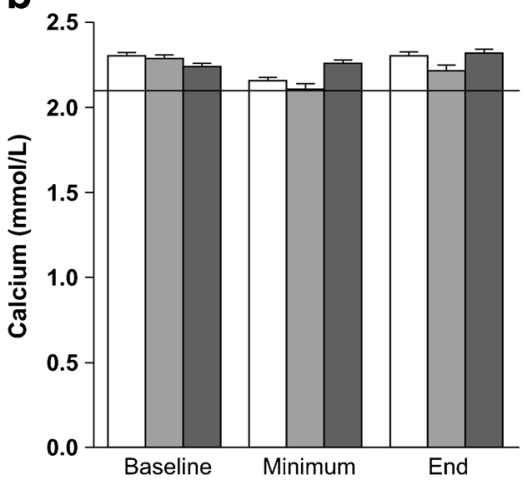

d

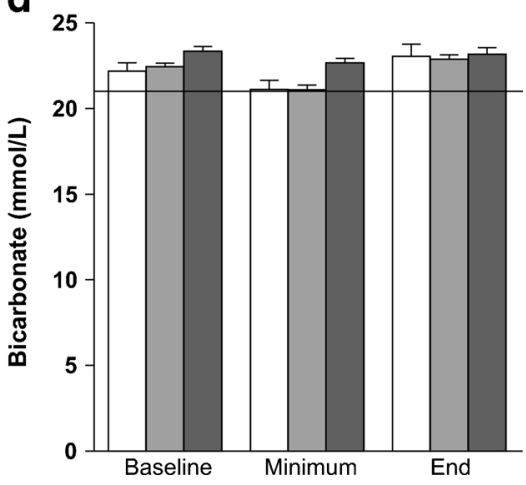

was accompanied by fever and exanthema, and voriconazole was additionally marked by skin photosensitization, increased sweats, and diarrhea. Other studies have shown a broad spectrum of side effects during voriconazole treatment. In a prospective multicenter trial involving 45 allogeneic stem cell transplant recipients with previous proven or probable invasive fungal infection that received voriconazole as secondary antifungal prophylaxis, abdominal disorders such as diarrhea, vomiting, abdominal pain, nausea, as well as pyrexia, headache, and rash were observed [35]. In another study of 69 pediatric patients with invasive fungal infections who were intolerant or refractory to conventional antifungal therapy and, therefore, received voriconazole as antifungal treatment, the most commonly reported adverse events in $33 \%$ of the patients were skin rash, abnormal vision, and a photosensitivity reaction [12]. In the present analysis, the toxicity profile during antifungal prophylaxis with posaconazole was comparable to voriconazole and itraconazole. Similar laboratory changes occurred within all three groups, showing elevation of liver enzymes significantly above normal values during antifungal monoprophylaxis without functional relevance. An increase of liver enzymes was also observed in a pilot study that analyzed the safety and efficacy of intravenous and oral itraconazole prophylaxis in pediatric hematopoietic stem cell transplantation [13]. During the antifungal therapy with voriconazole, $13.8 \%$ of the pediatric patients also experienced treatment-related adverse events with an increase of transaminases or bilirubin [12]. In a prospective study of hemato-oncological patients with GvHD during posaconazole prophylaxis, an increase of hepatic enzymes and bilirubinemia were observed [23]. Similar to our previous posaconazole analysis, we observed a significant increase of liver enzymes ALT and AST that were over the normal values during antifungal prophylaxis with posaconazole [24]. This significant increase was observed at a median of day 12 (range day 8-16) after the start of treatment with posaconazole, and decreased to normal values at a median of up to day 26 (range day 22-32) after the start of treatment with posaconazole. Renal parameters and electrolytes showed no clinically relevant changes in all three groups. In our analysis, an increase of CsA trough levels was observed in all three groups after the start of treatment with oral antifungal prophylaxis. This was not clinically relevant, although dosage reduction was required.

The observation of the increase in CsA level in the current analysis with the co-administration of posaconazole confirmed our observations from our first posaconazole analysis, where a dose reduction of $\mathrm{CsA}$ to $32 \%$ was required [24]. Another pharmacokinetic analysis showed that a CsA dose reduction of up to $50 \%$ was necessary with concomitant posaconazole treatment [36].

Despite the excellent efficacy of the three analyzed antifungal agents in this study, some azole-susceptible yeasts may be colonized or pathogenic. The comparison of 
antifungal monoprophylaxis with different azoles in immunocompromised patients showed a species-specific reduction in the numbers of colonizers [37]. However, there were occurrences of invasive fungal infections with Candida glabrata, most probably due to decreased susceptibility or the poor responsiveness of this species to the treatment with azoles. This represents a greater risk for the progression of invasive fungal infections. A multicenter study aimed at investigating the susceptibility distribution of antifungal agents observed patterns of complete parallel resistance more within azoles $(8.8 \%)$ than echinocandins $(1.7 \%)$ [38].

In summary, this analysis showed that all azoles proved to be very effective in the prevention of proven and probable fungal infections after allogeneic HSCT in pediatric patients.

To make further statements regarding efficacy, the analysis of a larger number of patients is required. Moreover, a drug monitoring of future prospective trials with posaconazole should be done in order to better understand the pharmacokinetic properties and interactions with other drugs (antibiotics, immunosuppressants) after HSCT.

Acknowledgments Preparation of the manuscript was funded, in part, by MSD Sharp \& Dohme GmbH, Germany.

Conflict of interest The authors declare that they have no competing interests.

Open Access This article is distributed under the terms of the Creative Commons Attribution License which permits any use, distribution, and reproduction in any medium, provided the original author(s) and the source are credited.

\section{References}

1. Steinbach WJ (2010) Invasive aspergillosis in pediatric patients. Curr Med Res Opin 26:1779-1787

2. Zaoutis T (2010) Candidemia in children. Curr Med Res Opin 26: $1761-1768$

3. Cuenca-Estrella M, Rodríguez-Tudela JL, Mellado E, MartínezSuárez JV, Monzón A (1998) Comparison of the in-vitro activity of voriconazole (UK-109,496), itraconazole and amphotericin B against clinical isolates of Aspergillus fumigatus. J Antimicrob Chemother 42:531-533

4. Espinel-Ingroff A, Canton E, Gibbs D, Wang A (2007) Correlation of Neo-Sensitabs tablet diffusion assay results on three different agar media with CLSI broth microdilution M27-A2 and disk diffusion M44-A results for testing susceptibilities of Candida spp. and Cryptococcus neoformans to amphotericin B, caspofungin, fluconazole, itraconazole, and voriconazole. J Clin Microbiol 45: 858-864

5. Espinel-Ingroff A, Boyle K, Sheehan DJ (2001) In vitro antifungal activities of voriconazole and reference agents as determined by NCCLS methods: review of the literature. Mycopathologia 150: $101-115$

6. Potter M, Donnelly JP (2004) The role of itraconazole in preventing and treating systemic fungal infections in immunocompromised patients. Acta Haematol 111:175-180
7. Glasmacher A, Prentice A, Gorschlüter M, Engelhart S, Hahn C, Djulbegovic B et al (2003) Itraconazole prevents invasive fungal infections in neutropenic patients treated for hematologic malignancies: evidence from a meta-analysis of 3,597 patients. J Clin Oncol 21:4615-4626

8. Winston DJ, Maziarz RT, Chandrasekar PH, Lazarus HM, Goldman M, Blumer JL et al (2003) Intravenous and oral itraconazole versus intravenous and oral fluconazole for long-term antifungal prophylaxis in allogeneic hematopoietic stem-cell transplant recipients. A multicenter, randomized trial. Ann Intern Med 138:705-713

9. Morgenstern GR, Prentice AG, Prentice HG, Ropner JE, Schey SA, Warnock DW (1999) A randomized controlled trial of itraconazole versus fluconazole for the prevention of fungal infections in patients with haematological malignancies. U.K. Multicentre Antifungal Prophylaxis Study Group. Br J Haematol 105:901-911

10. Vardakas KZ, Michalopoulos A, Falagas ME (2005) Fluconazole versus itraconazole for antifungal prophylaxis in neutropenic patients with haematological malignancies: a meta-analysis of randomisedcontrolled trials. Br J Haematol 131:22-28

11. Herbrecht R, Denning DW, Patterson TF, Bennett JE, Greene RE, Oestmann JW et al (2002) Voriconazole versus amphotericin B for primary therapy of invasive aspergillosis. N Engl J Med 347:408-415

12. Walsh TJ, Lutsar I, Driscoll T, Dupont B, Roden M, Ghahramani P et al (2002) Voriconazole in the treatment of aspergillosis, scedosporiosis and other invasive fungal infections in children. Pediatr Infect Dis J 21:240-248

13. Grigull L, Kuehlke O, Beilken A, Sander A, Linderkamp C, Schmid $\mathrm{H}$ et al (2007) Intravenous and oral sequential itraconazole antifungal prophylaxis in paediatric stem cell transplantation recipients: a pilot study for evaluation of safety and efficacy. Pediatr Transplant 11: 261-266

14. Cesaro S, Strugo L, Alaggio R, Cecchetto G, Rigobello L, Pillon M et al (2003) Voriconazole for invasive aspergillosis in oncohematological patients: a single-center pediatric experience. Support Care Cancer 11:722-727

15. Greenberg RN, Mullane K, van Burik JA, Raad I, Abzug MJ, Anstead G et al (2006) Posaconazole as salvage therapy for zygomycosis. Antimicrob Agents Chemother 50:126-133

16. Maertens J, Groll AH, Cordonnier C, de la Cámara R, Roilides E, Marchetti O (2011) Treatment and timing in invasive mould disease. J Antimicrob Chemother 66:i37-i43

17. Raad II, Hachem RY, Herbrecht R, Graybill JR, Hare R, Corcoran G et al (2006) Posaconazole as salvage treatment for invasive fusariosis in patients with underlying hematologic malignancy and other conditions. Clin Infect Dis 42:1398-1403

18. Raad II, Graybill JR, Bustamante AB, Cornely OA, Gaona-Flores V, Afif C et al (2006) Safety of long-term oral posaconazole use in the treatment of refractory invasive fungal infections. Clin Infect Dis 42: $1726-1734$

19. Schering Corporation (2008) Prescribing information for Noxafil (posaconazole) oral suspension. Schering Corporation, Kenilworth, NJ

20. Krieter P, Flannery B, Musick T, Gohdes M, Martinho M, Courtney R (2004) Disposition of posaconazole following single-dose oral administration in healthy subjects. Antimicrob Agents Chemother 48:3543-3551

21. Wexler D, Courtney R, Richards W, Banfield C, Lim J, Laughlin M (2004) Effect of posaconazole on cytochrome P450 enzymes: a randomized, open-label, two-way crossover study. Eur J Pharm Sci 21:645-653

22. Cornely OA, Maertens J, Winston DJ, Perfect J, Ullmann AJ, Walsh TJ et al (2007) Posaconazole vs. fluconazole or itraconazole prophylaxis in patients with neutropenia. N Engl J Med 356:348-359

23. Ullmann AJ, Lipton JH, Vesole DH, Chandrasekar P, Langston A, Tarantolo SR et al (2007) Posaconazole or fluconazole for prophylaxis in severe graft-versus-host disease. N Engl J Med 356: 335-347 
24. Döring M, Müller C, Johann PD, Erbacher A, Kimmig A, Schwarze $\mathrm{CP}$ et al (2012) Analysis of posaconazole as oral antifungal prophylaxis in pediatric patients under 12 years of age following allogeneic stem cell transplantation. BMC Infect Dis 12:263

25. de Pauw B, Walsh TJ, Donnelly JP, Stevens DA, Edwards JE, Calandra T et al (2008) Revised definitions of invasive fungal disease from the European Organization for Research and Treatment of Cancer/Invasive Fungal Infections Cooperative Group and the National Institute of Allergy and Infectious Diseases Mycoses Study Group (EORTC/ MSG) Consensus Group. Clin Infect Dis 46:1813-1821

26. Ascioglu S, Rex JH, de Pauw B, Bennett JE, Bille J, Crokaert F et al (2002) Defining opportunistic invasive fungal infections in immunocompromised patients with cancer and hematopoietic stem cell transplants: an international consensus. Clin Infect Dis 34:7-14

27. Cancer Therapy Evaluation Program, Division of Cancer Treatment and Diagnosis, National Cancer Institute, National Institutes of Health (2006) Common terminology criteria for adverse events v3.0 (CTCAE). DCTD, NCI, NIH, DHHS, Bethesda, MD. Available online at: http://ctep.cancer.gov/protocoldevelopment/ electronic_applications/docs/ctcaev3.pdf

28. Maertens J, Marchetti O, Herbrecht R, Cornely OA, Flückiger U, Frêre $P$ et al (2011) European guidelines for antifungal management in leukemia and hematopoietic stem cell transplant recipients: summary of the ECIL 3-2009 update. Bone Marrow Transplant 46:709-718

29. Cornely OA, Böhme A, Buchheidt D, Einsele H, Heinz WJ, Karthaus $M$ et al (2009) Primary prophylaxis of invasive fungal infections in patients with hematologic malignancies. Recommendations of the Infectious Diseases Working Party of the German Society for Haematology and Oncology. Haematologica 94:113-122

30. Tomblyn M, Chiller T, Einsele H, Gress R, Sepkowitz K, Storek J et al (2009) Guidelines for preventing infectious complications among hematopoietic cell transplantation recipients: a global perspective. Biol Blood Marrow Transplant 15:1143-1238
31. Lehrnbecher T, Attarbaschi A, Duerken M, Garbino J, Gruhn B, Kontny U et al (2010) Posaconazole salvage treatment in paediatric patients: a multicentre survey. Eur J Clin Microbiol Infect Dis 29: 1043-1045

32. Cesaro S, Milano GM, Aversa F (2011) Retrospective survey on the off-label use of posaconazole in pediatric hematology patients. Eur J Clin Microbiol Infect Dis 30:595-596

33. Faul F, Erdfelder E, Lang A-G, Buchner A (2007) G*Power 3: a flexible statistical power analysis program for the social, behavioral, and biomedical sciences. Behav Res Methods 39:175-191

34. Winston DJ, Bartoni K, Territo MC, Schiller GJ (2011) Efficacy, safety, and breakthrough infections associated with standard longterm posaconazole antifungal prophylaxis in allogeneic stem cell transplantation recipients. Biol Blood Marrow Transplant 17:507515

35. Cordonnier C, Rovira M, Maertens J, Olavarria E, Faucher C, Bilger $\mathrm{K}$ et al (2010) Voriconazole for secondary prophylaxis of invasive fungal infections in allogeneic stem cell transplant recipients: results of the VOSIFI study. Haematologica 95:1762-1768. doi:10.3324/ haematol.2009.020073

36. Sánchez-Ortega I, Vázquez L, Montes C, Patiño B, Arnan M, Bermúdez A et al (2012) Effect of posaconazole on cyclosporine blood levels and dose adjustment in allogeneic blood and marrow transplant recipients. Antimicrob Agents Chemother 56:6422-6424. doi:10.1128/AAC.01489-12

37. Mann PA, McNicholas PM, Chau AS, Patel R, Mendrick C, Ullmann AJ et al (2009) Impact of antifungal prophylaxis on colonization and azole susceptibility of Candida species. Antimicrob Agents Chemother 53:5026-5034. doi:10.1128/AAC.01031-09

38. Schmalreck AF, Willinger B, Haase G, Blum G, Lass-Flörl C, Fegeler W et al (2012) Species and susceptibility distribution of 1062 clinical yeast isolates to azoles, echinocandins, flucytosine and amphotericin B from a multi-centre study. Mycoses 55:e124e137. doi:10.1111/j.1439-0507.2011.02165.x 